\title{
A Study on the Evaluation Indicators for Developing Regional Tourism and Recreational Systems
}

\author{
Shao-Ping Wang \\ Ph.D. Student \\ Department of Business Management, Nanhua University \\ No.55, Sec. 1, Nanhua Rd., Dalin Township, Chiayi County 62249, Taiwan R.O.C. \\ Miao-Sheng Chen \\ Department of Business Management, Nanhua University \\ No.55, Sec. 1, Nanhua Rd., Dalin Township, Chiayi County 62249, Taiwan R.O.C.

\section{Mou-Jian Li} \\ Department of Business Management, Nanhua University \\ No.55, Sec. 1, Nanhua Rd., Dalin Township, Chiayi County 62249, Taiwan R.O.C.
}

Received: Oct. 26, 2018 Accepted: Feb. 28, 2019 Online published: Mar. 13, 2019

doi:10.5296/ijhrs.v9i2.14322 URL: https://doi.org/10.5296/ijhrs.v9i2.14322

\begin{abstract}
This study applied the analytic hierarchy process (AHP) to existing literature on developing regional tourism and recreational systems, dividing the evaluation indicators into five main criteria and 19 sub-criteria, including the "selection of geographical location," "development resources and facilities," "transport and services," "destination competitiveness," and "impact of recreational activities." Opinions of experts from academia, industry, and the government were collected to analytically weigh each indicator, providing a reference and evaluation basis for relevant institutions. The conclusion shows that Taiwanese people stress the convenience of round-trip transportation and services when making travel decisions.
\end{abstract}

Keywords: analytic hierarchy process, tourism and recreational systems, transport and services, destination competitiveness, impacts of recreational activities, travel decisions 


\section{Introduction}

The hierarchy of needs proposed by A. H. Maslow divides human needs into five tiers, moving from (lower) physiological to (higher) psychological needs. The need for leisure and recreation is a higher need, felt by humans once their physiological and safety needs are fulfilled. When the purpose of life changes from being survival-oriented to focusing on quality of life (QoL), leisure and recreational behaviors serve as a key to improving QoL (Wu, 2004).

In recent years, the tourism and recreational industry in Taiwan has had only a partial understanding of diverse regional development. However, there has been a lack of appropriate indicative planning and management for implementing the Visitor Experience and Resource Protection (VERP) framework (Wang, 2000), which has led conflicts between recreational experience and natural resources.

This study's objective was to construct an indicative development evaluation model for regional tourism and recreational system. Based on a literature review of academic theories and related discussions in domestic and foreign studies, five main criteria and 19 sub-criteria were identified with which to evaluate relevant institutions. The opinions of experts from different sectors were collected from a questionnaire, and the analytic hierarchy process (AHP) was used to weight the responses and determine the appropriate direction for future institutional development. This provides a reference with which to evaluate regional tourism and recreational systems.

\section{Literature Review}

\subsection{Selection of Geographical Location}

When tourists select a travel destination, they make the decision according to their personal socio-economic variables, as well as the appeal and accessibility of the recreational region. The development of the region affects local development and government revenue through profit-sharing (e.g., income and employment), operating income, and control rights. Recreational facilities can be categorized as water-based recreational facilities, land-based recreational facilities, and water- and land-based recreational facilities (Wu, Lin, \& Huang, 2005). Wu (1991) has observed that the implementation of a development program can be divided into four phases: feasibility, suitability, technicality, and realizability.

Lin and Yen (1994) believed that it is preferable to have as few structures on the existing land as possible. Land with easily obtainable ownership and that can be (or has been) altered for recreational purposes should be prioritized. With respect to the method of land acquisition, private land can be legally expropriated, while a public land can be appropriated by the local government through the coordination of the tourism authority and the land use or management authority (Wu, 1991). Natural landscape resources are considered one of the key factors of travel motivation, allowing tourists to get close to nature, enjoy natural beauty, and thus learn to protect the environment (Kim, 2003). 


\subsection{Development Resources and Facilities}

Researchers have pointed out many considerations to keep in mind when allocating development resources. Kim et al. (2002) asserted that optimized services and management systems, convenient accommodation, catering equipment, parking space, and clean and comfortable guest rooms are necessary for a recreational facility. Wu (1991) pointed out that the operation of a recreational facility should entail the setting up of service centers, regional road planning, and overall planning of the public facilities and services system. Regarding management, a specialized institution should be established to coordinate the operation of different units, and clear environmental regulations and overall facility regulations should be formulated. $\mathrm{Wu}$, Tsao, and Yen (1999) believed that establishing a recreational facility requires a large area of land and enormous capital; due to cost considerations, it is impossible to set up a facility in every administrative region. From the viewpoint of entrepreneurs or the government, it is hoped that the largest number of tourists can be served using the least number of recreational facilities.

Recreational carrying capacity is one indicator of the quality of recreation provided by a recreational region. It is only when the carrying load is kept within the allowed range that the environment of the recreational region can maintain ecological balance and tourists can receive substantial benefits from recreation. The environmental design regulations for a recreational zone include its location and features, current development and usage, types of current activities, expected sites of development and activities to be introduced there, types of facilities, principles of facility selection, and standards of facility design (Wu, 1991).

\subsection{Transport and Services}

Wang, Liu, and Li, (1993) observed that during the development of a tourism and recreational system, transportation facilities have the most obvious and direct impact on the transition of spatial structure. As they connect and integrate different regions, system segmentation is no longer evident. The transportation network serves as a means for tourists to travel to a recreational facility. A direct and convenient transportation system for a primary market - i.e., a densely populated major city — should be given the highest priority (Lin and Yen, 1994). The duration of travel and the comfort of the travel experience directly affect tourists' willingness to choose a destination and the length of time they spend there. The shorter the travel time, the more recreation time they spend at the destination (Wu, 1991).

Wu et al. (1999) argued that traffic conditions also have a certain impact on attracting tourists. The amount of traffic will influence the quality of travel and the selection of a travel destination, and it is one of the specific factors that motivate tourists to visit Taiwan (Kim et al., 2002; Song and Song., 2011).

\subsection{Destination Competitiveness}

Ritchie and Crouch (2003) defined destination competitiveness as "the ability of a destination to enhance its well-being through asset management, production processes, and attractors, and integrate it into the overall socio-economic system." 
Among the existing theoretical models of this concept, the most complete are: 1) the "concept model" constructed by Ritchie and Crouch (Crouch and Ritchie, 1999; Ritchie and Crouch, 2000, 2003), which includes core resources and attractors, supporting factors and resources, destination policies on tourism management, qualifying determinants of planning and development, overall global environment, and individual competitive environment; and 2) the "integrated model" built by Dwyer and Kim (Dwyer and Kim, 2003; Kim and Dwyer, 2003), which includes core resources, supporting resources, destination management, situational conditions, and market demand.

\subsection{Impact of Recreational Activities}

$\mathrm{Wu}$ (1991, 2013) believed that, during the development of recreational facilities, consideration should be given to the level of impact on factors like landform, geology, meteorology, vegetation, and water resources, as well as the potential impact on social culture, including interpersonal relationships, social structure, pace of life, migration and employment, customs and habits, power distribution, and anomic behaviors.

$\mathrm{Wu}$ (2013) believed that recreational activities will increase the number of public facilities and promote local tourism activities and the conservation of rural environment; however, they may also have negative impacts, such as an imbalance of recreational carrying capacity and environment damage caused by tourists. While economic development brings benefits like local revenue, an increase in assets, and development of relevant industries, there are also adverse effects such as inflation, illegal businesses, unregulated hawkers, and damage to the ecosystem.

\section{Materials and Methods}

The targets of the questionnaire included representative experts from academia, industry, and the government in Taiwan. After the opinions of these experts were collected, a nominal scale was used to perform pairwise comparisons between the elements, based on AHP. AHP was appropriate because it is mainly applied to situations with uncertainty and decision problems with multiple evaluation factors (Deng and Ceng, 1989). Paired matrices were established after quantification, from which the eigenvector of each matrix was obtained as the priority among the elements in the hierarchy. The maximum eigenvalue was calculated to evaluate the relative weights of the consistency indexes of the comparison matrix, providing reference indexes for decision-makers to make decisions, a process described by Rong (2011). This analytical procedure can be found in Figure 1.
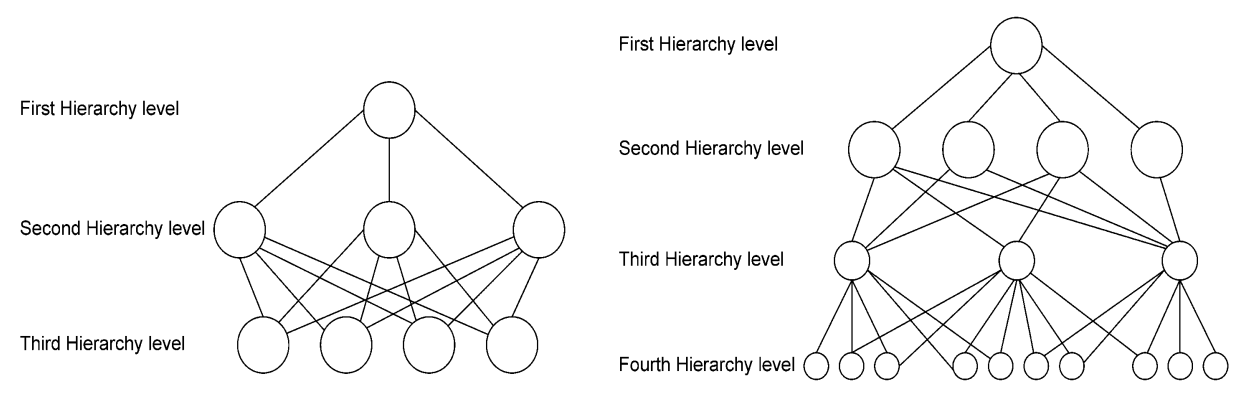

Figure 1. Complete (left) and incomplete (right) hierarchical structure 
The AHP evaluation scale includes five levels - "equal importance," "moderate importance," "strong importance," "very strong importance," and "extreme importance"-quantified into the weight values of $1,3,5,7$, and 9 on the nominal scale. There are also four intermediate values of 2, 4, 6, and 8 in between five levels. The meaning of each level is shown in Table 1.

Table 1. Significance and description of evaluation scale

\begin{tabular}{lll}
\hline Evaluation scale & Definition & Description \\
\hline 1 & Equal Importance & $\begin{array}{l}\text { Levels of contribution of the two alternatives } \\
\text { being compared are equally important }\end{array}$ \\
\hline 5 & Weak Importance & $\begin{array}{l}\text { Experience and judgment slightly prefer one } \\
\text { alternative }\end{array}$ \\
\hline 7 & Essential Importance & $\begin{array}{l}\text { Experience and judgment strongly prefer one } \\
\text { alternative }\end{array}$ \\
\hline 9 & Very Strong & $\begin{array}{l}\text { An extremely strong preference for one alternative } \\
\text { is demonstrated }\end{array}$ \\
\hline $2,4,6,8$ & Absolute Importance & $\begin{array}{l}\text { There is sufficient evidence to affirm the absolute } \\
\text { preference for one alternative }\end{array}$ \\
\hline
\end{tabular}

The AHP is typically performed under the following seven assumptions (Deng and Ceng, 1989):

1. Each system or problem can be broken down into measurable classes or components, forming a directional hierarchical network.

2. In the hierarchical structure, elements at each level are independent. Evaluation can be performed using some or all of the elements of the upper level as a benchmark.

3. During the rating process, the absolute numerical scale can be converted into a ratio scale.

4. After pairwise comparison, the reciprocal matrix is symmetrical to the main diagonal. It can be processed with a positive reciprocal matrix.

5. The preference relation satisfies transitivity, but it is difficult to possess complete transitivity. Therefore, intransitivity is allowed, but the degree of consistency must be tested to determine the degree of inconsistency.

6. The priority of elements is obtained using the weighting principle.

7. An element, as long as it appears in the hierarchical structure, is deemed to be related to the overall evaluation of the goal structure, regardless of its priority.

This study gathered academic theories and related domestic and overseas studies, and established a hierarchical framework based on various indicators and dimensions (see Figure 1). After collecting the opinions of experts from academia, industry, and government sources, the weight of the main criteria (indicators) and sub-criteria (dimensions) was analyzed using Super Decisions version 2.2.6, a decision support software.

\section{Results and Discussion}

\subsection{Results and Analyses}

The targets of this questionnaire included representative experts from the academia, industry, 


\section{Macrothink}

International Journal of Human Resource Studies

ISSN 2162-3058 2019, Vol. 9, No. 2

and government. A total of 20 questionnaires were sent out, among which 17 were returned, and 1 was invalid. The response rate was $80 \%$. What follows is a list of the weight of each main criterion and sub-criterion:

1. Selection of geographical location (0.11622):

(a) Factors of recreational activities and methods of development (0.53338)

(b) Roles of the supply sector and methods of land obtainment (0.32124)

(c) Natural and cultural landscape environment (0.14538)

2. Development resources and facilities (0.14744):
(a) Tourism policy trends and related regulations $(0.38505)$
(b) Operation and management of supporting facilities and infrastructure (0.31513)
(c) Recreational carrying capacity and environmental design regulations (0.29982)

3. Transport and services $(0.44063)$ :
(a) Maximization of travel convenience (0.40111)
(b) Optimizing tourism services $(0.36974)$
(c) Minimizing total travel distance (0.15169)
(d) Minimizing the number of service facilities (0.07927)

4. Destination competitiveness (0.14358):
(a) Market demand for tourism and tourists' perception and preferences (0.33977)
(b) Planning and development of destination policies (0.15922)
(c) Supporting factors and resources (0.14318)
(d) Core resources and attractors $(0.13813)$
(e) Individual competitive environment (0.13719)
(f) Overall global environment (0.08251).

5. Impacts of recreational activities (0.15213):

(a) Impacts on the natural environment (0.46258)

(b) Socio-economic impacts $(0.27208)$

(c) Socio-cultural impacts $(0.26535)$

As shown by these results, the weight of "transport and services" was significantly higher than other criteria, showing that the first-hand experience of tourists during their trips to and from a destination should be the most important consideration in developing recreational facilities. "Maximizing travel convenience" and "optimizing the quality of tourism services" 
also ranked higher than other criteria, showing the growing importance of quality of life to Taiwanese people.

According to the analysis of weights of the criteria in this study, "factors of recreational activities and methods of development" obtained the highest score, representing the need and preference of Taiwanese people for considering the nature of recreation, which has a significant impact on the factors of recreational activities and methods of development.

\subsection{Discussion}

This study attempted to construct an indicative model for developing regional tourism and recreational systems. The weight of each indicator and dimension was analyzed with reference to existing literature and expert opinions, using the analytic hierarchy process. The results show that the most important criterion was "transport and services," followed by "impacts of recreational activities," "development resources and facilities," "destination competitiveness," and "selection of geographical location." This demonstrates that Taiwanese people stress the convenience of round-trip transportation and services when making travel decisions. For this reason, regional recreation facilities should be set up as centers of attraction for the entire region, to expand the interlinkages of existing transportation routes, improve the services of public transport, implement a benchmark for maintaining recreational carrying capacity, and make adjustments and revisions according to the situation. All these benefits together would help maintain the goal of sustainable operation.

\section{References}

Crouch, G. I., \& Ritchie, J. R. B. (1999). Tourism, competitiveness and societal prosperity. Journal of Business Research, 44(3), 137-152. https://doi.org/10.1016/S0148-2963(97)00196-3

Deng, Z., \& Ceng, G. (1989). Connotation and Application of Hierarchical Analysis (AHP). Chinese Journal of Statistics, 27(6), 5-20.

Dwyer, L., \& Kim, C. (2003) Destination competitiveness: Determinants and indicators. Current Issues in Tourism, 6(5), 369-413. https://doi.org/10.1080/13683500308667962

Kim, C., \& Dwyer, L. (2003). Destination competitiveness and bilateral tourism flows between Australia and Korea. Journal of Tourism Studies, 14(2), 55-67.

Kim, H. J., Jung, K. J., Yu, B. P., Cho, C. G., Choi, J. S., \& Chung, H. Y. (2002). Modulation of redox-sensitive transcription factors by calorie restriction during aging. Mechanisms of ageing and development, 123(12), 1589-1595. https://doi.org/10.1016/S0047-6374(02)00094-5

Lin, Y. J., \& Yen, J. (1994). Resort base and its site selection. Journal of Outdoor Recreation Study, 7(1), 17-33.

Ritchie, J. R. B., \& Crouch, G. I. (2000). The competitive destination, a sustainable perspective. Tourism Management, 21(1), 1-7. 


\section{Macrothink}

International Journal of Human Resource Studies

ISSN 2162-3058 2019, Vol. 9, No. 2

Ritchie, J. R. B., \& Crouch, G. I. (2003). The competitive destination. Cambridge, MA: Athenaeum Press, Gateshead.

Rong, T. (2011). Expert choice's application on analytic hierarchy process (AHP). Taipei: Wu-Nan Book Inc.

Song, Y., \& Song, Y. (2011). Research on thrust and pull motivation, perceived value, satisfaction and loyalty--Taking foreign tourist travel in Taiwan as an example. Journal of Tourism and Travel Research, 6(2), 21-40.

Wang, H., Liu, H., \& Li, C. J. (1993). Development trends and suggested strategies for recreation/tourism system in Taiwan. Journal of Outdoor Recreation Study, 6(3), 1-23.

Wang, Z. (2000). Study on the application of VERP management model on Taroko National Park (Commissioned Research Report). Taiwan: Taroko National Park Management Office.

$\mathrm{Wu}, \mathrm{K}$. (1991). Study on consideration factors of developing combined tourism recreation area (doctoral dissertation). National Cheung Kung University, Tainan, Taiwan.

Wu, S. T. (2013) Marine recreational activity impact on Kengting National Park, Taiwan. Journal of Hospitality and Management Tourism, 4(1), 1-8. https://doi.org/10.5897/JHMT12.028

Wu, T. (2004). A study on constructing a Taiwan travel and leisure indicator system. Journal of Outdoor Recreation Study, 17(2), 49-68.

Wu, T. H., Tsao, C. C., \& Yen, T. H. (1999). Applying multi-objective decision making technique on the determination of locations for recreational facilities. Journal of the Chinese Institute of Industrial Engineers, 16(4), 495-506. https://doi.org/10.1080/10170669.1999.10432674

Wu, X., Lin, Y., \& Huang, W. (2005). Residents of the aboriginal community in Taroko National Park recognize and demand the development of ecotourism. Outdoor Recreation Research, 18(4), 47-67.

\section{Copyright Disclaimer}

Copyright for this article is retained by the author(s), with first publication rights granted to the journal.

This is an open-access article distributed under the terms and conditions of the Creative Commons Attribution license (http://creativecommons.org/licenses/by/4.0/). 